\title{
Arbutus unedo L. and Ocimum basilicum L. as sources of natural preservatives for food industry: A case study using loaf bread
}

\author{
Sallawi Takwa ${ }^{\text {a, b }}$, Cristina Caleja a, João C.M. Barreira a , Marina Sokovićc ${ }^{c}$, Lotfi Achour ${ }^{\mathrm{b}}$, \\ Lillian Barros $^{\text {a, **, Isabel C.F.R. Ferreira }}{ }^{\text {a, * }}$ \\ a Centro de Investigação de Montanha (CIMO), ESA, Instituto Politécnico de Bragança, Campus de Santa Apolónia, 5300-253 Bragança, Portugal \\ b Laboratoire de Recherche "Bioressources": Biologie Intégrative \& Valorisation", Institut Supérieur de Biotechnologie de Monastir, Avenue Tahar Hadded, BP \\ 74, 5000, Université de Monastir, Monastir, Tunisia \\ ' University of Belgrade, Department of Plant Physiology, Institute for Biological Research "Siniša Stanković", Bulevar Despota Stefana 142, 11000 Belgrade, \\ Serbia
}

\section{A R T I C L E I N F O}

\section{Article history:}

Received 19 July 2017

Received in revised form 27 September 2017

Accepted 27 September 2017

Available online 29 September 2017

\section{Keywords:}

Strawberry tree

Basil

Antioxidant preservatives

Loaf bread

\begin{abstract}
A B S T R A C T
The aim of this work was to demonstrate the antioxidant potential, antimicrobial and the absence of toxicity of the ethanol extracts obtained from strawberry tree fruits and basil leaves, using optimal conditions. Subsequently, the extracts rich in catechin, from strawberry tree fruits, and rosmarinic acid from basil leaves, were incorporated as natural ingredients in loaf bread samples, with two objectives: to functionalize bread, introducing bioactive properties; and as natural ingredients with preservation capacity. Three more groups: control (without addition of any additive), bread incorporated with ascorbic acid - E300 and bread incorporated with potassium sorbate - E202 and for each group were 3 different times were analyzed: immediately after incorporation and after 3 and 7 days. Both natural extracts presented antioxidant activity, without toxicity up to the maximal tested dose $(400 \mu \mathrm{g} / \mathrm{mL})$, and the main compounds present were catechin and rosmarinic acid, respectively. The breads incorporated with the natural extracts, especial basil, presented a higher antioxidant capacity than the loaf breads incorporated with ascorbic acid and potassium sorbate. Overall, the obtained results demonstrate that these extracts could be used in the development of new bread replacing the synthetic preservatives, without interfering with nutritional characteristics.
\end{abstract}

(c) 2017 Elsevier Ltd. All rights reserved.

\section{Introduction}

The overwhelming growth of the world population over the past few decades associated with consumer concern has forced the food industry to find alternatives to synthetic additives in order to meet consumers' expectations and ensuring the global quality of the food products including aspect, texture and flavor (Motarjemi, Moy, \& Todd, 2014). Due to great advances in food technology, there are currently a wide variety of additives, being estimated over 2500 different types that are used by the food industry to achieve the desired effects in food (Branen, Davidson, Salminen, \& Thorngate, 2001). Antimicrobials, antioxidants and antibrowning agents are among the additives mostly used by the food industry to preserve

\footnotetext{
* Corresponding author.

** Corresponding author.

E-mail addresses: lillian@ipb.pt (L. Barros), iferreira@ipb.pt (I.C.F.R. Ferreira).
}

products for longer periods (Carocho, Barreiro, Morales, \& Ferreira, 2014).

However, despite the existence of increasingly demanding legislation and control, several studies continue to address the toxicity that synthetic additives pose to human health and the interactions that different chemical additives may have with each other, increasing some toxicity effects (Viator, Blitstein, Brophy, \& Fraser, 2015). Currently, all new food additives undergo a safety assessment to minimize any potential adverse effect to human health. To assess potential risks to human health, a number of tests are conducted including using animal testing, evaluating the potential for critical chronic toxicity, genetic damage, or cancer and any possible effect on the development and reproduction damages (Tomaska \& Tharwa, 2014). For example, ascorbic acid (used as an antioxidant) and potassium sorbate (used as preservative), are very common additives in food processing, but their use is restricted in terms of amounts in food products by the two major regulators of food additives, the Food and Drug Administration (FDA) and the 
European Food Safety Authority (EFSA) (Stopforth, Sofos, \& Busta, 2005).

To overcome this problem, natural extracts appear as alternatives, providing an additional value to the final products due to their bioactive properties (Caleja et al., 2016a). Natural preservatives are found in the majority of plants, fungi, microorganisms, and even in some animal tissues (Carocho, Morales, \& Ferreira, 2015a). These types of compounds have gained increasing interest from the food industry for direct application or in synergy with other natural or chemical additives. Among the various studied effects, the high antioxidant and antimicrobial potential is the most widely reported (Carocho et al., 2014). Besides that, natural preservatives seem to receive approval from consumers who increasingly care about their health and well-being and as such, prefer food labeled as healthier and more natural (Caleja et al., 2016b).

Arbutus unedo L. (strawberry tree) and Ocimum basilicum L. (basil), are examples of important sources of bioactive natural molecules. The fruits of $A$. unedo are described as rich in nutritional properties and have several medicinal effects, as astringent, diuretic and antiseptic properties and especially effects on cancer and cardiovascular disease (Oliveira et al., 2011). The protective effects have been attributed to the presence of phenolic compounds; in particular, some authors focused on catechins that have attracted attention, particularly due to their relative high antioxidant activity (Gomes, 2011). A study developed by Barros, Carvalho, Morais, and Ferreira (2010) has proved the high antioxidant capacity of these fruits that has so much called the attention of the scientific community. Rosmarinic acid has been characterized as one of the most abundant caffeic acid esters present in Ocinium spp. and the presence of this compound has been highly investigated (Carocho et al., 2016; Vlase et al., 2014). The presence of this molecule in medicinal plants, herbs and spices has been associated with beneficial and promotional effects in health. Furthermore, a study performed by Carocho et al. (2016) proved that the incorporation of basil extracts into cheese, added bioactive effects to this product.

In this study, our purpose was to obtain an extract rich in catequin from Arbutus unedo and an extract rich in rosmarinic acid from Ocimum basilicum, evaluate their toxicity, antioxidant and antimicrobial properties, and validate their preserving use by incorporation in loaf bread, in comparison with the use of commercial additives.

\section{Materials and methods}

\subsection{Standards and reagents}

HPLC-grade acetonitrile was obtained from Merck (Darmstadt, Germany). 2,2- Diphenyl-1-picrylhydrazyl (DPPH) was obtained from Alfa Aesar (Ward Hill, MA, USA). Phenolic standards were bought from Extrasynthèse (Genay, France). The fatty acids methyl ester (FAME) reference standard mixture 37 (standard 47885-U) was purchased from Sigma-Aldrich (St. Louis, MO, USA), as also other individual fatty acid isomers, nitric acid, formic acid, Trolox (6-hydroxy-2,5,7,8- tetramethylchroman-2-carboxylic acid), Ellipticine and sulforhodamine B. Mueller-Hinton agar (MH) and malt agar (MA) were obtained from the Institute of Immunology and Virology, Torlak (Belgrade, Serbia). Fetal bovine serum (FBS), lglutamine, nonessential amino acids solution (2 mM), penicillin/ streptomycin solution (100 U/mL and $100 \mathrm{mg} / \mathrm{mL}$, respectively), RPMI-1640 and Dulbecco's Modified Eagle Medium (DMEM) media were acquired from Thermo Fischer Scientific (Waltham, MA, USA). Sulphuric, hydrochloric and nitric acid were obtained from Fisher Scientific (Waltham, MA, USA). All other reagents were purchased from specialized retailers. Water was treated in a Milli-Q water purification system (TGI Pure Water Systems, Greenville, SC, USA)

\subsection{Natural ingredients: phenolic-rich extracts}

\subsubsection{Preparation}

The fruits of Arbutus unedo L. (strawberry tree) were gathered in the Natural Park of Montesinho territory, in Trás-os-Montes, Northeastern Portugal and the botanical identification was confirmed by Dr. Ana Maria Carvalho (School of Agriculture, Polytechnic Institute of Bragança, Portugal) according with a previous report of the authors (Guimarães et al., 2013). The fruits were lyophilized (FreeZone 4.5, Labconco, Kansas KansasCity, MO, USA) and stored in a deepfreezer at $-20^{\circ} \mathrm{C}$ for subsequent analyses. Commercial samples of Ocinium basilicum (basil) leaves were bought in a local supermarket. The dried samples were powdered ( 20 mesh; Ultra Centrifugal Mill ZM 200, Porto, Portugal).

The extract rich in catechin from $A$. unedo was obtained following the optimized extraction described by Albuquerque et al. (2017). The lyophilized powdered fruit samples ( $5 \mathrm{~g}$ ) was placed in a beaker with $100 \mathrm{~mL}$ of ethanol:water 23:77( $\mathrm{v} / \mathrm{v})$. The beaker was placed in a thermostatic water bath at $80{ }^{\circ} \mathrm{C}$ under continuous electro-magnetic stirring for $93 \mathrm{~min}$. The collected extracts were filtered through a Whatman paper filter No 4 and evaporated at $40^{\circ} \mathrm{C}$ in a rotary evaporator (Büchi R-210, Flawil, Switzerland), until ethanol removal, afterwards the aqueous extract was frozen then lyophilized.

The extract rich in rosmarinic acid was obtained from 0 . basilicum following a maceration extraction procedure. The sample $(1 \mathrm{~g})$ was extracted with $30 \mathrm{~mL}$ of ethanol:water 80:20 (v/v) at room temperature, $150 \mathrm{rpm}$, for $1 \mathrm{~h}$. The extract was filtered through Whatman $n^{\circ} 4$ paper. The residue was then re-extracted twice with additional $30 \mathrm{~mL}$ portions of ethanol:water 80:20 (v/v). The combined extracts were evaporated at $35^{\circ} \mathrm{C}$ (rotary evaporator Buchi R210) to remove ethanol. Afterwards, the aqueous extract was frozen and the samples were lyophilized.

\subsubsection{Chemical characterization}

The dry lyophilized extracts were re-dissolved in the extraction solvents, filtered through a $0.22 \mu \mathrm{m}$ nylon filter and submitted to LC-DAD-ESI/MSn analysis. The chromatographic data were acquired from Dionex Ultimate 3000 UPLC (Thermo Scientific, San Jose, CA, USA), as previously described by Bessada, Barreira, Barros, Ferreira, and Oliveira (2016). Double online detection was carried out using a DAD detector (280 and $370 \mathrm{~nm}$, as preferred wavelengths) and with a mass spectrometer (MS). The MS detection was performed in negative mode, using a Linear Ion Trap LTQ XL mass spectrometer (ThermoFinnigan, San Jose, CA, USA) equipped with an ESI source. Catechin and rosmarinic acid were identified by comparing their retention times, UV-vis and mass spectra with those obtained from standard compounds. For quantitative analysis, a calibration curve for catechin and rosmarinic acid was constructed based on the UV signal. The results were expressed as $\mathrm{mg} /$ $\mathrm{g}$ of extract.

\subsubsection{Evaluation of toxicity}

The cytotoxicity was evaluated following the methodology previously described by Guimarães et al. (2013) and using porcine liver, which was acquired from certified abattoirs. A phase-contrast microscope was used to monitor the growth of the cell cultures. They were sub-cultured and plated in 96 well plates (density of $1.0 \times 104$ cells/well). DMEM medium was used, with $10 \%$ of FBS, 100 $\mathrm{U} / \mathrm{mL}$ of penicillin and $100 \mu \mathrm{g} / \mathrm{mL}$ of streptomycin. Ellipticine was used as a positive control, and the results were expressed in in $\mathrm{GI}_{50}$ values in $\mu \mathrm{g} / \mathrm{mL}$ (sample concentration that inhibited $50 \%$ of the net 
cell growth).

\subsubsection{Evaluation of antioxidant properties}

The lyophilized samples were re-dissolved in ethanol $(5 \mathrm{mg} / \mathrm{mL})$ and successively diluted until determination of $\mathrm{EC}_{50}$ values (sample concentration providing $50 \%$ of antioxidant activity or 0.5 of absorbance in the reducing power assay).

DPPH radical-scavenging activity and reducing power were evaluated using ELX800 microplate Reader (Bio-Tek Instruments, Inc. Winooski, VT, USA) at 515 and $690 \mathrm{~nm}$, respectively. $\beta$-Carotene bleaching inhibition and lipid peroxidation inhibition, using the thiobarbituric acid reactive substances - TBARS, were evaluated spectrophotometrically at 470 and $532 \mathrm{~nm}$, respectively. The complete protocols were previously described by the authors Barros et al. (2013). Trolox was used as positive control in all the assays.

\subsubsection{Evaluation of antimicrobial properties}

Following the procedure previously described by the authors (Soković, Glamoćlija, Marin, Brkić, \& van Griensven, 2010), antibacterial activity was evaluated against four Gram-negative bacteria: Escherichia coli (ATCC 35210), Pseudomonas aeruginosa (ATCC 27853), Salmonella typhimurium (ATCC 13311), Enterobacter cloacae (ATCC 35030), and four Gram-positive bacteria: Staphylococcus aureus (ATCC 6538), Bacillus cereus (clinical isolate), Micrococcus flavus (ATCC 10240), and Listeria monocytogenes (NCTC 7973). Following the same reference, the minimum inhibitory (MIC) and minimum bactericidal (MBC) concentrations were determined and streptomycin and ampicillin were used as positive controls.

Following the procedure previously described by the authors (Soković \& van Griensven, 2006), antifungal activity was evaluated against eight fungi: Aspergillus fumigatus (ATCC 1022), Aspergillus ochraceus (ATCC 12066), Aspergillus versicolor (ATCC 11730), Aspergillus niger (ATCC 6275), Aspergillus flavus (ATCC 9643), Cladosporium cladosporioides (ATCC 11278), Penicillium funiculosum (ATCC 36839) and Penicillium verrucosum var. cyclopium (food isolate). Following the same reference, the minimum inhibitory (MIC) and minimum fungicidal (MFC) concentrations were determined and bifonazole and ketokonazole were used as positive controls.

\subsection{Incorporation of additives in loaf bread}

\subsubsection{Preparation of the loaf bread samples}

The loaf bread samples were prepared with a bread maker (Tefal home bread XXL, model: 573902) and by following the recipe: $325 \mathrm{~mL}$ of water, $18 \mathrm{~g}$ of oil, $11 \mathrm{~g}$ of salt, $20 \mathrm{~g}$ of sugar, $25 \mathrm{~g}$ of milk, $600 \mathrm{~g}$ of flour and $4 \mathrm{~g}$ of yeast. The synthetic and natural antioxidants were added to the mixture at $1.2 \mathrm{~g}$ for each bread $(1 \mathrm{~kg})$, which is the maximum quantity permitted for sorbate potassium (synthetic additive).

Five groups of bread samples were prepared: i) control bread (bread without any incorporation of natural or synthetic ingredient); ii) bread incorporated with ascorbic acid (E300); iii) bread incorporated with potassium sorbate (E202); iv) bread incorporated with an extract rich in catechin; and v) bread incorporated with an extract rich in rosmarinic acid. All samples were prepared in triplicate in order to be able to evaluate three different storage times. All the samples were submitted to physico-chemical, nutritional, and antioxidant activity evaluation, immediately after preparation and after 3 and 7 days of storage at $4{ }^{\circ} \mathrm{C}$.

\subsubsection{Evaluation of color parameters and $\mathrm{pH}$ of the bread samples along storage time}

The color of the samples was measured in three different points on the top, botton and inside using a colorimeter (model CR-400, Konica Minolta Sensing Inc. Tokyo, Japan). The illuminate $C$ was used and a diaphragm aperture of $8 \mathrm{~mm}$ and previously calibrated against a standard white tile. The CIE $L^{*}$ (lightness), $a^{*}$ (greenness/ redness), $b^{*}$ (blueness/yellowness) color space values were registered using a data software "Spectra Magic Nx" (version CM-S100W 2.03.0006) (Fernandes et al., 2012).

The $\mathrm{pH}$ of the samples was measured with a HI $99161 \mathrm{pH}-$ meter (Hanna Instruments, Woonsocket, Rhode Island, USA) by inserting the tip of the measuring pen into the already cooked bread. The measurement was performed in triplicate for each of the samples.

\subsection{Evaluation of the nutritional composition and antioxidant activity of different samples along storage time}

Following the AOAC methods (AOAC, 2016), the contents of protein, fat, carbohydrates and ash, was determined. Total energy was calculated following the equation: Energy (kcal) $=4 \times(\mathrm{g}$ proteins $+\mathrm{g}$ carbohydrates $)+9 \times(\mathrm{g}$ lipids). Total protein content $(\mathrm{N} \times 5.70)$ was calculated as nitrogen content by the Kjeldahl method, while crude fat relied on the extraction of dried samples with petroleum ether using a Soxhlet apparatus. Finally, the ash content was determined by incineration at $550 \pm 15{ }^{\circ} \mathrm{C}$ (Barros et al., 2013).

Fatty acids were determined, after Soxhlet extraction, by gas chromatography coupled to flame ionization detector (GC-FID), identified by comparison with standards (standard 47885, SigmaAldrich, St. Louis, Missouri, USA) and expressed as relative percentages of each fatty acid (Barros et al., 2013).

Free sugars were determined in defatted samples by HPLC coupled to a refraction index (RI) detector (Barros et al., 2013), identified by comparison with standards, and further considering the internal standard (melezitose) were quantified ( $\mathrm{g} / 100 \mathrm{~g}$ of bread).

For evaluation of antioxidant activity, the samples were submitted to DPPH and reducing power assays, described in Section 2.2.3.

\subsection{Statistical analysis}

All statistical tests were performed at a 5\% significance level using IBM SPSS Statistics for Windows, version 22.0. (IBM Corp. Armonk, NY, USA).

Except for antimicrobial assays results, data were expressed as mean \pm standard deviation, maintaining the significant numbers allowed by the magnitude of the standard deviation.

The results obtained in the biological activity of $A$. unedo fruit and $O$. basilicum leaves extracts were compared by $t$-Student test, while an analysis of variance (ANOVA) with type III sums of squares was performed using the general linear model (GLM) procedure, to compare all parameters assayed in the prepared loaf breads. The dependent variables were analyzed using 2-way ANOVA with the factors "bread type" (BT) and "storage time" (ST). When a statistically significant interaction was detected for these two factors, they were evaluated simultaneously by the estimated marginal means plots for all levels of each factor. Furthermore, if no statistical significant interaction is found, the means were compared using Tukey's multiple comparison test, with a previous assessment of the equality of variances through a Levene's test.

In addition, a linear discriminant analysis (LDA) was used to compare the effect of BT and ST over all assayed parameters. A stepwise technique was applied, considering the Wilks' $\Lambda$ test with the usual probabilities of $\mathrm{F}$ ( 3.84 to enter and 2.71 to be removed) for variable selection. This procedure is based in sequential forward selection and backward elimination steps, where the inclusion of a 
new variable requires verifying the significance of all previously selected variables (Zielinski et al., 2014). In general, it was intended to estimate the relationship between single categorical dependent variables (bread types) and the quantitative independent variables (results obtained in laboratorial assays). The generated outputs allowed determining which independent variables contributed more to the differences in the average score profiles of the different bread samples. To verify the significance of the canonical discriminating functions, Wilk's $\Lambda$ test was used. A leaving-one-out cross validation procedure was carried out to assess the model performance.

\section{Results and discussion}

\subsection{Biological activity of the plant extracts}

As previously explained, it was intended to evaluate the effects of incorporating the extracts of Arbutus unedo fruits (extract rich in catechin) and Ocimum basilicum leaves (extract rich in rosmarinic acid) in the preservation and functionalization of loaf bread. The potential functionalizing effect of both extract types became evident in previously published research reports (Albuquerque et al., 2017; Andrade, Gil, Breitenfeld, Domingues, \& Duarte, 2009; Barros et al., 2010; Carocho et al., 2016; Fortalezas et al., 2010). Owing to current consuming trends, which progressively require longer shelf-lives for bread products, those effects were evaluated in three different periods (baking day, after 3 days of storage and after 7 days of storage).

The extracts were obtained using ethanol:water mixtures $(23 \%$ of ethanol in A. unedo fruits; $80 \%$ of ethanol in 0 . basilicum leaves). Before proceeding to their incorporation, extracts were individually characterized regarding antioxidant (Table 1), antimicrobial (Table 2) and cytotoxic activities. Furthermore, the quantities of rosmarinic acid $(45.3 \pm 0.6 \mathrm{mg}$ of rosmarinic acid/g of extract) and catechin $(25.7 \pm 0.2 \mathrm{mg}$ of catechin acid/g of extract) obtained from the extracts of $O$. basilicum leaves and $A$. unedo fruits, respectively, were also determined.

The extracts obtained from 0 . basilicum leaves showed significantly higher antioxidant activity, as indicated by DPPH scavenging activity, reducing power and $\beta$-carotene bleaching inhibition; on the other hand, the ability to inhibit TBARS formation was similar in both extracts.

Besides their high antioxidant activity, the extracts from A. unedo rich in catechin and $O$. basilicum rich in rosmarinic acid, showed also a high antibacterial activity, often comparable to that achieved with the standard antibiotics streptomycin and ampicillin. Among Gram-positive bacteria, Pseudomonas aeruginosa and Salmonella typhimurium were the most sensitive to the extracts of A. unedo fruit and $O$. basilicum leaves, respectively. In both cases, MIC values were lower than those obtained with ampicillin (and also with streptomycin in the case of $O$. basilicum leaves). In general, the antibacterial activity of $O$. basilicum leaves extracts was higher than that of $A$. unedo fruit extracts (except regarding MIC in Pseudomonas aeruginosa and Enterobacter cloacae).

On the other hand, the extracts obtained from $A$. unedo fruits achieved higher antifungal activity, demonstrating particularly high activity against Aspergillus ochraceus, Aspergillus flavus and Cladosporium cladosporioides (Table 2). In fact, the results obtained for the indicated species were comparable, or even better, than those produced by the tested standards.

The higher antioxidant and antibacterial activities measured in the extracts of $O$. basilicum leaves might be associated to the high contents in phenolic acids, particularly in rosmarinic acid (Carocho et al., 2016), whilst the activity of $A$. unedo fruits should be explained, in part, by the presence of significant levels of catechins (Albuquerque et al., 2017). None of the assayed extracts showed cytotoxicity up to the maximal assayed concentrations $(400 \mu \mathrm{g} /$ $\mathrm{mL})$.

\subsection{Characterization of different types of functionalized bread}

Bread represents a staple food all over the world, thereby being a suitable food matrix to assay different incorporation processes (e.g. preservative ingredient, functionalization/fortification approaches) (Bolarinwa, Aruna, \& Raji, 2017; Singh, Jha, Chaudhary, \& Upadhyay, 2012). Concomitantly, people are progressively receptive to food products prepared with natural ingredients in substitution to general synthetic compounds, which are often associated with unwanted effects (Carocho et al., 2014). In addition to the potential health effects conveyed by the functionalizing agents, the rheological and technological properties of food products themselves might also be improved (Berdahl, Nahas, \& Barren, 2010; Caleja et al., 2015; Carocho et al., 2015b; Sciarini, Ribotta, León, \& Pérez, 2012).

In the present work, five bread types (BT) were prepared: i) control (bread without any type of incorporated extract); ii) bread with A. unedo fruits extract (rich in catechin); iii) bread with 0 . basilicum leaves extract (rich in rosmarinic acid); vi) bread with ascorbic acid; and v) bread with potassium sorbate. In addition to the evaluation of each extract type on different chemical and bioactive parameters, it was also intended to verify how these effects evolved throughout time, specifically considering 3 periods: preparation day, 3 days after preparation and 7 days after preparation.

From a practical point of view, the effect of each extract should be evaluated independently of storage time (ST). The interaction among factors $(\mathrm{BT} \times \mathrm{ST})$ was evaluated to assess possible differentiated effects, i.e., if the influence of one factor showed different variations depending on the level of the other factor. When a significant interaction was found $(p<0.050)$, no multiple comparisons can be performed. In those cases, the effect of each factor was assessed by interpreting the estimated marginal means (EMM)

Table 1

Antioxidant activity ( $\mathrm{EC}_{50}$ values, $\mu \mathrm{g} / \mathrm{mL}$ extract) of the extracts of $A$. unedo fruits and $O$. basilicum leaves. Values are given as mean \pm standard deviation.

\begin{tabular}{|c|c|c|c|c|c|}
\hline & & DPPH scavenging Activity & Reducing power & $\beta$-carotene bleaching inhibition & TBARS formation inhibition \\
\hline \multirow{2}{*}{\multicolumn{2}{|c|}{$\begin{array}{l}\text { Arbutus unedo fruit } \\
\text { Ocimum basilicum leaves }\end{array}$}} & $595 \pm 10$ & $328 \pm 2$ & $2169 \pm 25$ & $347 \pm 17$ \\
\hline & & $261 \pm 4$ & $136 \pm 1$ & $1008 \pm 53$ & $351 \pm 20$ \\
\hline \multirow[t]{2}{*}{$p$-value $(\mathrm{n}=18)$} & Homoscedasticity $^{\mathrm{a}}$ & 0.023 & 0.024 & 0.003 & 0.871 \\
\hline & $t$-student test $\mathrm{t}^{\mathrm{b}}$ & $<0.001$ & $<0.001$ & $<0.001$ & 0.624 \\
\hline
\end{tabular}

\footnotetext{
${ }^{a}$ Homoscedasticity plant species was tested by Levene test: homoscedasticity, $p>0.05$; heteroscedasticity, $p<0.05$.

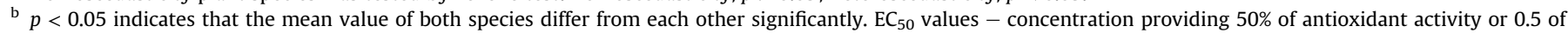

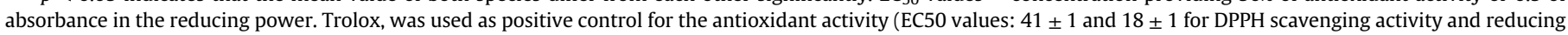
power, respectively).
} 


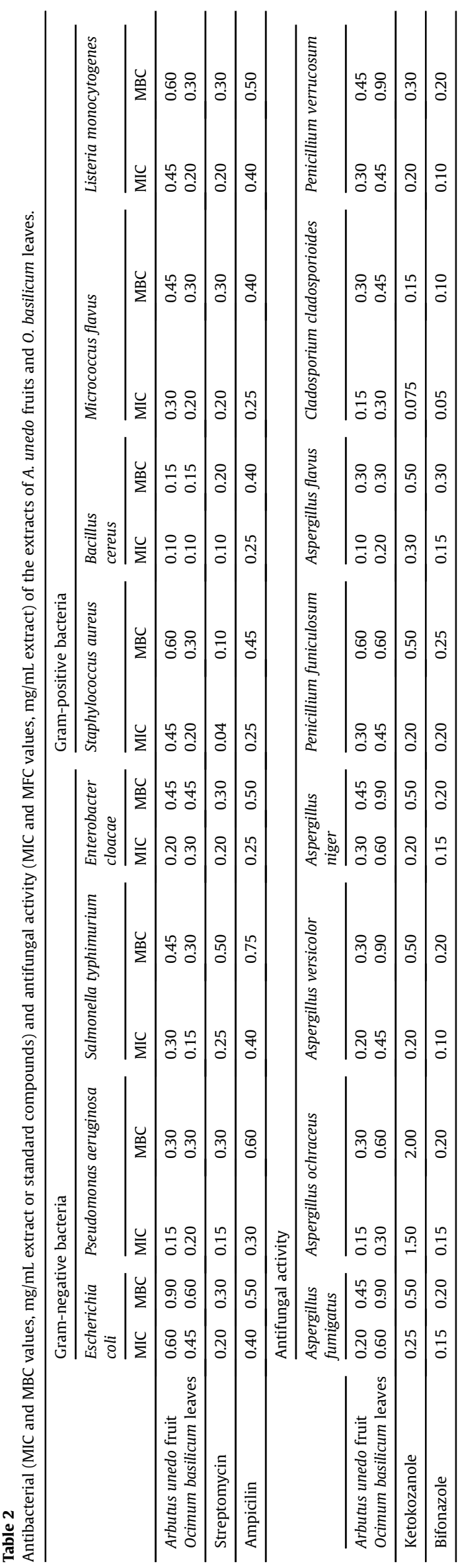

plots.

Regarding nutritional composition (Table 3), the interaction among factors was significant in all cases, showing that the variation in water, fat, protein, ash, carbohydrates and energy throughout time depended of BT, thereby hindering the possibility of identifying general tendencies. Comparing individual factors, BT had a higher effect than ST, as the variations induced by BT were significant in all cases, while ST produced a significant effect only in water, protein and ash.

Owing to the relevancy of the visual appearance of bread, its color parameters ( $L^{*}$ : lightness, $a^{*}$ : redness and $b^{*}$ : blueness) were evaluated on the top crust, interior and bottom crust (Table 4). The cooperative effect of BT and ST was also significant in most cases, except $L^{*}$ and $b^{*}$ in the bottom crust. Among color parameters, $L^{*}$ showed the most marked differences, with higher values in control bread, regarding the effect of BT, but specially with lower values in samples stored during 7 days, in what concerns ST effect. In either case, the effects over color parameters were more noticeable in bread interior, as crust color is especially dependent on baking temperature and time (Debonne, Van Bockstaele, Philips, De Leyn, \& Eeckhout, 2017), which were rigorously maintained in the study reported herein.

The profiles in individual sugars (Table 5) and fatty acids (major compounds are presented in Table 6) were also assessed in order to verify their integrity along ST. Both components are prone to oxidation, representing one of the main indicators of adequate conservation of food products (Barreira, Pereira, Oliveira, \& Ferreira, 2010; Pereira et al., 2016). Nevertheless, and despite the existence of significant differences resulting from BT and ST, the profiles in sugars and fatty acids were maintained nearly unchanged inclusively in control bread. In addition, the interaction among factors was significant in all cases, thereby hampering the possibility of obtaining general conclusions.

Finally, the antioxidant activity of different BT was evaluated to compare the effects of each incorporated extract. More than evaluating improvements in comparison to control bread, which would be easily anticipated, it was intended to verify potential differences among natural extracts and commercial compounds. Regarding DPPH scavenging activity (Fig. 1A), bread prepared with $O$. basilicum extract achieved the best results, showing to be more effective than ascorbic acid and potassium sorbate. However, the ability to scavenge DPPH radical decreased along time in all BT. On the other hand, no significant differences were found in the reducing power of all functionalized breads (Fig. 1B), which however maintained similar activity throughout ST.

Furthermore, none of the functionalized breads showed cytotoxicity up to the maximal assayed concentrations $(400 \mu \mathrm{g} / \mathrm{mL})$ and the quantities of rosmarinic acid (bread with $O$. basilico leaves extract) and catechin (bread with $A$. unedo fruit extract) were also maintained along ST, which could be considered as an indicator of the maintenance of the antimicrobial activity (in line with the observed with the antioxidant activity).

\subsection{Linear discriminant analysis}

In the previous section, several statistically significant differences were found in different assayed parameters (either in result of BT or ST). However, it would be useful to have a thorough characterization of each BT, considering its effects on all parameters simultaneously, in that way verifying which of them had higher contribution to the detected differences. Accordingly, a linear discriminant analysis (LDA) was performed to evaluate the linkage between BT (categorical dependent variables) and the matrix of obtained results (quantitative independent variables). The significant independent variables were selected following the 
Table 3

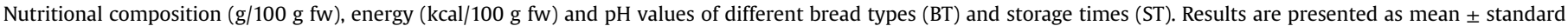
deviation. $^{\text {a }}$

\begin{tabular}{|c|c|c|c|c|c|c|c|c|}
\hline & & Water & Fat & Protein & Ash & Carbohydrates & Energy & $\mathrm{pH}$ \\
\hline \multirow[t]{6}{*}{ BT } & Control bread & $30 \pm 1$ & $1.7 \pm 0.2$ & $6.9 \pm 0.5$ & $1.9 \pm 0.2$ & $59 \pm 2$ & $280 \pm 7$ & $5.7 \pm 0.3$ \\
\hline & Bread with $A$. unedo & $32 \pm 1$ & $1.8 \pm 0.2$ & $6.9 \pm 0.2$ & $1.7 \pm 0.2$ & $57 \pm 1$ & $274 \pm 4$ & $5.8 \pm 0.3$ \\
\hline & Bread with 0 . basilicum & $30 \pm 1$ & $2.3 \pm 0.1$ & $7.2 \pm 0.3$ & $2.0 \pm 0.4$ & $59 \pm 1$ & $285 \pm 5$ & $5.7 \pm 0.4$ \\
\hline & Bread with ascorbic acid & $32 \pm 1$ & $2.1 \pm 0.2$ & $6.8 \pm 0.2$ & $1.9 \pm 0.1$ & $57 \pm 1$ & $274 \pm 5$ & $5.6 \pm 0.3$ \\
\hline & Bread with potassium sorbate & $29 \pm 1$ & $2.1 \pm 0.2$ & $7.0 \pm 0.5$ & $2.2 \pm 0.3$ & $60 \pm 1$ & $286 \pm 5$ & $5.7 \pm 0.2$ \\
\hline & ANOVA $p$-value $(\mathrm{n}=27)^{\mathrm{b}}$ & $<0.001$ & $<0.001$ & 0.013 & $<0.001$ & $<0.001$ & $<0.001$ & 0.157 \\
\hline \multirow[t]{4}{*}{ ST } & 0 days & $31 \pm 2$ & $2.1 \pm 0.3$ & $6.9 \pm 0.2$ & $2.1 \pm 0.3$ & $58 \pm 2$ & $278 \pm 7$ & $5.3 \pm 0.1$ \\
\hline & 3 days & $31 \pm 2$ & $2.0 \pm 0.3$ & $6.8 \pm 0.5$ & $1.7 \pm 0.2$ & $58 \pm 2$ & $279 \pm 7$ & $5.8 \pm 0.1$ \\
\hline & 7 days & $30 \pm 2$ & $2.0 \pm 0.3$ & $7.1 \pm 0.4$ & $1.9 \pm 0.2$ & $59 \pm 1$ & $282 \pm 7$ & $6.0 \pm 0.2$ \\
\hline & ANOVA $p$-value $(\mathrm{n}=45)^{\mathrm{c}}$ & 0.021 & 0.436 & 0.005 & $<0.001$ & 0.063 & 0.082 & $<0.001$ \\
\hline $\mathrm{BT} \times \mathrm{ST}$ & $p$-value $(\mathrm{n}=135)^{\mathrm{d}}$ & $<0.001$ & $<0.001$ & $<0.001$ & $<0.001$ & $<0.001$ & $<0.001$ & $<0.001$ \\
\hline
\end{tabular}

fw-freah weight.

${ }^{\text {a }}$ Results are reported as mean values of each bread type (BT), including results from 0, 3 and 7 days, and mean values of each storage time (ST), considering all bread types in each period.

b If $p<0.05$, the corresponding parameter presented a significantly different value for at least one bread type.

c If $p<0.05$, the corresponding parameter presented a significantly different value for at least one storage time.

d If $p<0.05$, the interaction among factors is significant; in this case, no multiple comparisons can be performed.

Table 4

Color parameters of different bread types (BT) and storage times (ST). Results are presented as mean \pm standard deviation. ${ }^{\mathrm{a}}$

\begin{tabular}{|c|c|c|c|c|c|c|c|c|c|c|}
\hline & & \multicolumn{3}{|c|}{ Top crust } & \multicolumn{3}{|c|}{ Bottom crust } & \multicolumn{3}{|c|}{ Bread interior } \\
\hline & & $L^{*}$ & $a^{*}$ & $b^{*}$ & $L^{*}$ & $a^{*}$ & $b^{*}$ & $L^{*}$ & $a^{*}$ & $b^{*}$ \\
\hline \multirow[t]{6}{*}{ BT } & Control bread & $58 \pm 4$ & $13 \pm 1$ & $33 \pm 3$ & $40 \pm 4 \mathrm{a}$ & $14 \pm 1$ & $24 \pm 3 a b$ & $68 \pm 3$ & $-0.7 \pm 0.2$ & $17 \pm 2$ \\
\hline & Bread with $A$. unedo & $52 \pm 3$ & $15 \pm 2$ & $33 \pm 2$ & $40 \pm 4 a b$ & $14 \pm 1$ & $25 \pm 2 \mathrm{a}$ & $61 \pm 5$ & $0.6 \pm 0.1$ & $17 \pm 2$ \\
\hline & Bread with 0 . basilicum & $55 \pm 4$ & $14 \pm 1$ & $31 \pm 3$ & $38 \pm 3 b c$ & $14 \pm 1$ & $23 \pm 3 b$ & $62 \pm 5$ & $0.6 \pm 0.2$ & $21 \pm 2$ \\
\hline & Bread with ascorbic acid & $55 \pm 4$ & $12 \pm 2$ & $32 \pm 4$ & $36 \pm 3 d$ & $14 \pm 1$ & $23 \pm 2 b$ & $65 \pm 4$ & $1.2 \pm 0.3$ & $21 \pm 2$ \\
\hline & Bread with potassium sorbate & $55 \pm 5$ & $16 \pm 2$ & $33 \pm 4$ & $37 \pm 3 \mathrm{~cd}$ & $15 \pm 1$ & $24 \pm 3 \mathrm{ab}$ & $69 \pm 5$ & $1.0 \pm 0.3$ & $21 \pm 1$ \\
\hline & ANOVA $p$-value $(\mathrm{n}=27)^{\mathrm{b}}$ & $<0.001$ & $<0.001$ & 0.163 & $<0.001$ & $<0.001$ & 0.042 & $<0.001$ & $<0.001$ & $<0.001$ \\
\hline \multirow[t]{4}{*}{ ST } & 0 days & $56 \pm 4$ & $14 \pm 2$ & $33 \pm 3$ & $40 \pm 3 a$ & $14 \pm 1$ & $25 \pm 2 \mathrm{a}$ & $68 \pm 4$ & $0.5 \pm 0.5$ & $19 \pm 3$ \\
\hline & 3 days & $56 \pm 4$ & $14 \pm 3$ & $32 \pm 3$ & $40 \pm 3 a$ & $15 \pm 1$ & $25 \pm 2 \mathrm{a}$ & $66 \pm 5$ & $0.5 \pm 0.5$ & $19 \pm 3$ \\
\hline & 7 days & $52 \pm 4$ & $15 \pm 2$ & $32 \pm 3$ & $35 \pm 2 b$ & $14 \pm 1$ & $22 \pm 2 b$ & $61 \pm 5$ & $0.5 \pm 0.5$ & $20 \pm 3$ \\
\hline & ANOVA $p$-value $(\mathrm{n}=45)^{\mathrm{c}}$ & $<0.001$ & 0.006 & 0.289 & $<0.001$ & $<0.001$ & $<0.001$ & $<0.001$ & 0.552 & 0.921 \\
\hline $\mathrm{BT} \times \mathrm{ST}$ & $p$-value $(\mathrm{n}=135)^{\mathrm{d}}$ & $<0.001$ & $<0.001$ & $<0.001$ & 0.125 & $<0.001$ & 0.221 & $<0.001$ & $<0.001$ & $<0.001$ \\
\hline
\end{tabular}

${ }^{\text {a }}$ Results are reported as mean values of each bread type (BT), including results from 0, 3 and 7 days, and mean values of each storage time (ST), considering all bread types in each period.

$\mathrm{b}$ If $p<0.05$, the corresponding parameter presented a significantly different value for at least one bread type.

${ }^{c}$ If $p<0.05$, the corresponding parameter presented a significantly different value for at least one storage time.

d If $p<0.05$, the interaction among factors is significant; in this case, no multiple comparisons can be performed.

Table 5

Individual sugars (g/100 g fw) of different bread types (BT) and storage times (ST). Results are presented as mean \pm standard deviation. ${ }^{\mathrm{a}}$

\begin{tabular}{|c|c|c|c|c|c|c|c|}
\hline & & Fructose & Glucose & Sucrose & Maltose & Trehalose & Total sugars \\
\hline \multirow[t]{6}{*}{ BT } & Control bread & $1.6 \pm 0.1$ & $0.56 \pm 0.02$ & $1.1 \pm 0.1$ & $3.4 \pm 0.3$ & $0.15 \pm 0.01$ & $6.9 \pm 0.4$ \\
\hline & Bread with A. unedo & $1.6 \pm 0.1$ & $0.57 \pm 0.03$ & $1.2 \pm 0.1$ & $3.7 \pm 0.2$ & $0.16 \pm 0.02$ & $7.3 \pm 0.2$ \\
\hline & Bread with 0 . basilicum & $1.7 \pm 0.1$ & $0.58 \pm 0.05$ & $1.1 \pm 0.1$ & $3.5 \pm 0.1$ & $0.16 \pm 0.02$ & $7.0 \pm 0.2$ \\
\hline & Bread with ascorbic acid & $1.3 \pm 0.1$ & $0.58 \pm 0.02$ & $1.2 \pm 0.1$ & $3.2 \pm 0.1$ & $0.13 \pm 0.01$ & $6.4 \pm 0.2$ \\
\hline & Bread with potassium sorbate & $1.7 \pm 0.1$ & $0.68 \pm 0.04$ & $1.2 \pm 0.1$ & $3.5 \pm 0.1$ & $0.14 \pm 0.01$ & $7.2 \pm 0.2$ \\
\hline & ANOVA $p$-value $(\mathrm{n}=27)^{\mathrm{b}}$ & $<0.001$ & $<0.001$ & $<0.001$ & $<0.001$ & $<0.001$ & $<0.001$ \\
\hline \multirow[t]{4}{*}{ ST } & 0 days & $1.7 \pm 0.2$ & $0.58 \pm 0.05$ & $1.1 \pm 0.1$ & $3.5 \pm 0.3$ & $0.15 \pm 0.02$ & $7.1 \pm 0.5$ \\
\hline & 3 days & $1.6 \pm 0.1$ & $0.59 \pm 0.05$ & $1.2 \pm 0.1$ & $3.5 \pm 0.2$ & $0.16 \pm 0.02$ & $7.0 \pm 0.3$ \\
\hline & 7 days & $1.5 \pm 0.1$ & $0.61 \pm 0.05$ & $1.1 \pm 0.1$ & $3.4 \pm 0.1$ & $0.15 \pm 0.01$ & $6.8 \pm 0.2$ \\
\hline & ANOVA $p$-value $(\mathrm{n}=45)^{\mathrm{c}}$ & $<0.001$ & 0.014 & 0.114 & 0.003 & 0.063 & $<0.001$ \\
\hline $\mathrm{BT} \times \mathrm{ST}$ & $p$-value $(\mathrm{n}=135)^{\mathrm{d}}$ & $<0.001$ & $<0.001$ & $<0.001$ & $<0.001$ & $<0.001$ & $<0.001$ \\
\hline
\end{tabular}

fw-freah weight.

${ }^{\text {a }}$ Results are reported as mean values of each bread type (BT), including results from 0, 3 and 7 days, and mean values of each storage time (ST), considering all bread types in each period.

$\mathrm{b}$ If $p<0.05$, the corresponding parameter presented a significantly different value for at least one bread type.

${ }^{c}$ If $p<0.05$, the corresponding parameter presented a significantly different value for at least one storage time.

${ }^{\mathrm{d}}$ If $p<0.05$, the interaction among factors is significant; in this case, no multiple comparisons can be performed. 
Table 6

Major fatty acids (relative percentage) of different bread types (BT) and storage times (ST). Results are presented as mean \pm standard deviation. ${ }^{\text {a }}$

\begin{tabular}{|c|c|c|c|c|c|c|c|c|c|}
\hline & & C16:0 & C18:0 & $\mathrm{C} 18: 1$ & $\mathrm{C} 18: 2$ & $\mathrm{C} 22: 0$ & SFA & MUFA & PUFA \\
\hline \multirow[t]{6}{*}{ BT } & Control bread & $15.1 \pm 0.2$ & $5.2 \pm 0.5$ & $37 \pm 2$ & $26 \pm 1$ & $3.5 \pm 0.4$ & $28 \pm 1$ & $40 \pm 2$ & $32 \pm 3$ \\
\hline & Bread with A. unedo & $15.0 \pm 0.1$ & $5.0 \pm 0.2$ & $36 \pm 1$ & $26 \pm 1$ & $3.5 \pm 0.1$ & $28 \pm 1$ & $36 \pm 5$ & $36 \pm 5$ \\
\hline & Bread with 0 . basilicum & $15.0 \pm 0.2$ & $4.9 \pm 0.1$ & $37 \pm 1$ & $26 \pm 1$ & $3.6 \pm 0.1$ & $28 \pm 1$ & $39 \pm 1$ & $33 \pm 1$ \\
\hline & Bread with ascorbic acid & $15.4 \pm 0.5$ & $5.2 \pm 0.1$ & $36 \pm 1$ & $26 \pm 1$ & $3.7 \pm 0.1$ & $29 \pm 1$ & $39 \pm 1$ & $33 \pm 1$ \\
\hline & Bread with potassium sorbate & $15.1 \pm 0.5$ & $5.1 \pm 0.3$ & $36 \pm 2$ & $26 \pm 1$ & $3.7 \pm 0.2$ & $28 \pm 1$ & $39 \pm 1$ & $33 \pm 3$ \\
\hline & ANOVA $p$-value $(\mathrm{n}=27)^{\mathrm{b}}$ & 0.004 & 0.007 & $<0.001$ & 0.691 & 0.035 & 0.084 & $<0.001$ & $<0.001$ \\
\hline \multirow[t]{4}{*}{ ST } & 0 days & $15.1 \pm 0.2$ & $5.2 \pm 0.5$ & $37 \pm 2$ & $26 \pm 1$ & $3.7 \pm 0.2$ & $29 \pm 1$ & $37 \pm 4$ & $34 \pm 5$ \\
\hline & 3 days & $14.9 \pm 0.3$ & $4.9 \pm 0.2$ & $36 \pm 1$ & $27 \pm 1$ & $3.6 \pm 0.2$ & $28 \pm 1$ & $38 \pm 1$ & $34 \pm 1$ \\
\hline & 7 days & $15.4 \pm 0.5$ & $5.1 \pm 0.2$ & $37 \pm 1$ & $26 \pm 1$ & $3.5 \pm 0.3$ & $29 \pm 1$ & $39 \pm 1$ & $32 \pm 2$ \\
\hline & ANOVA $p$-value $(\mathrm{n}=45)^{\mathrm{c}}$ & $<0.001$ & 0.001 & $<0.001$ & $<0.001$ & $<0.001$ & $<0.001$ & 0.002 & 0.004 \\
\hline$\overline{\mathrm{BT} \times \mathrm{ST}}$ & $p$-value $(\mathrm{n}=135)^{\mathrm{d}}$ & $<0.001$ & $<0.001$ & $<0.001$ & $<0.001$ & $<0.001$ & $<0.001$ & $<0.001$ & $<0.001$ \\
\hline
\end{tabular}

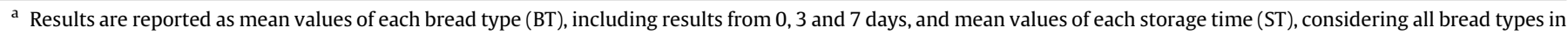
each period.

${ }^{b}$ If $p<0.05$, the corresponding parameter presented a significantly different value for at least one bread type.

c If $p<0.05$, the corresponding parameter presented a significantly different value for at least one storage time.

${ }^{d}$ If $p<0.05$, the interaction among factors is significant; in this case, no multiple comparisons can be performed.

\section{DPPH scavenging activity}

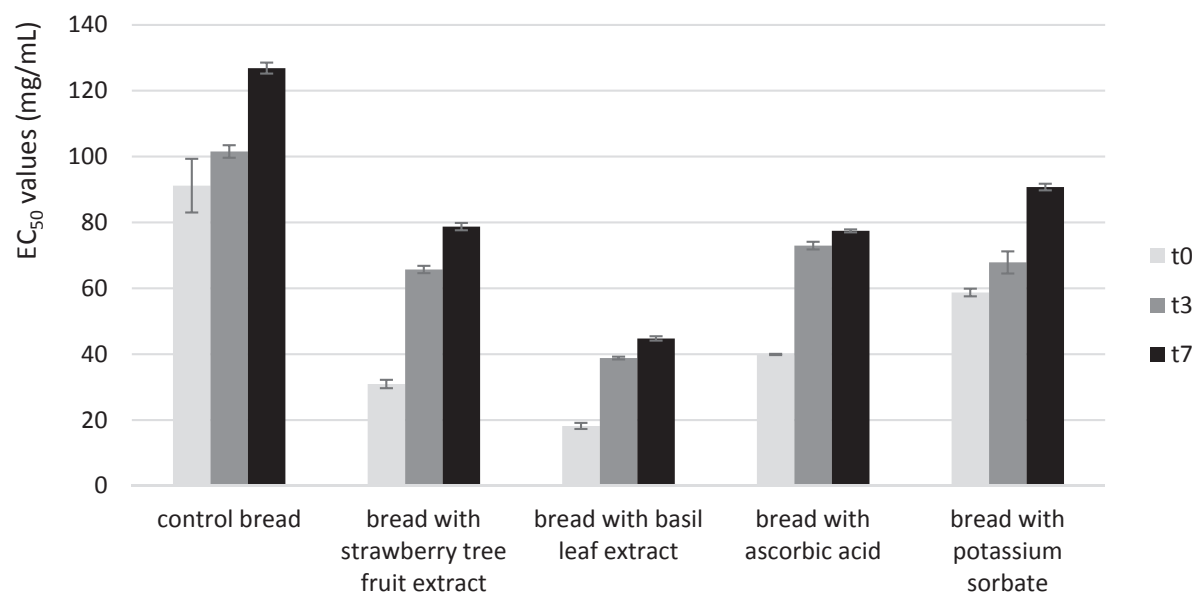

$\mathbf{A}$

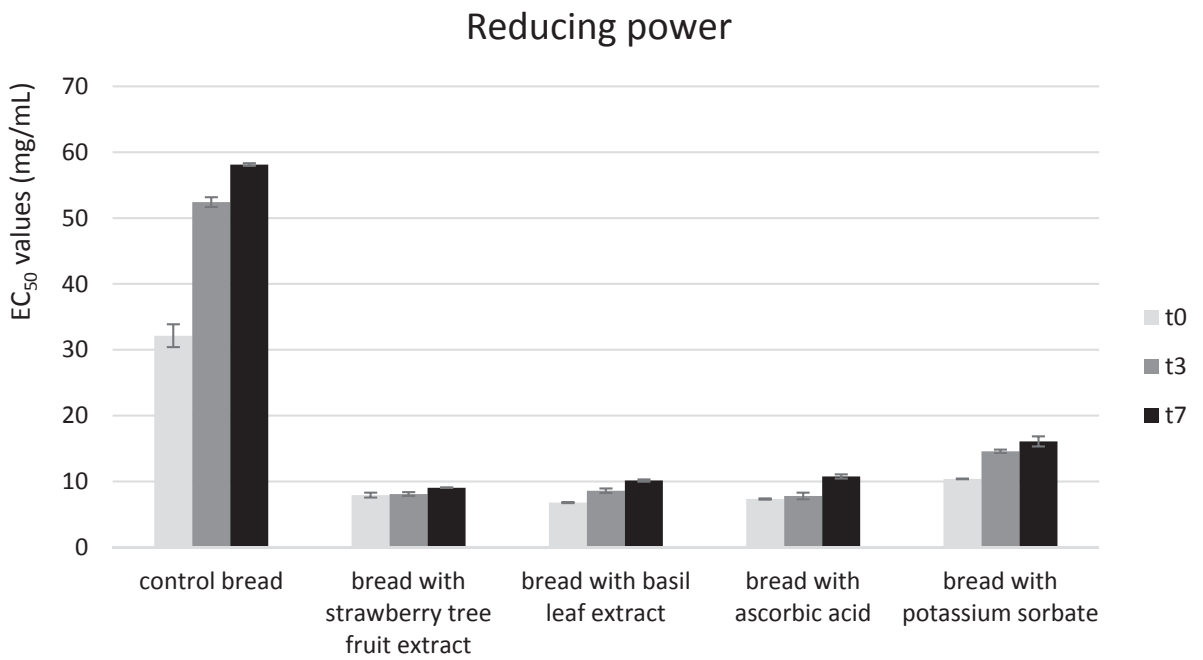

Fig. 1. DPPH scavenging activity (A) and reducing power (B) of different bread types assayed in three consecutive periods. 


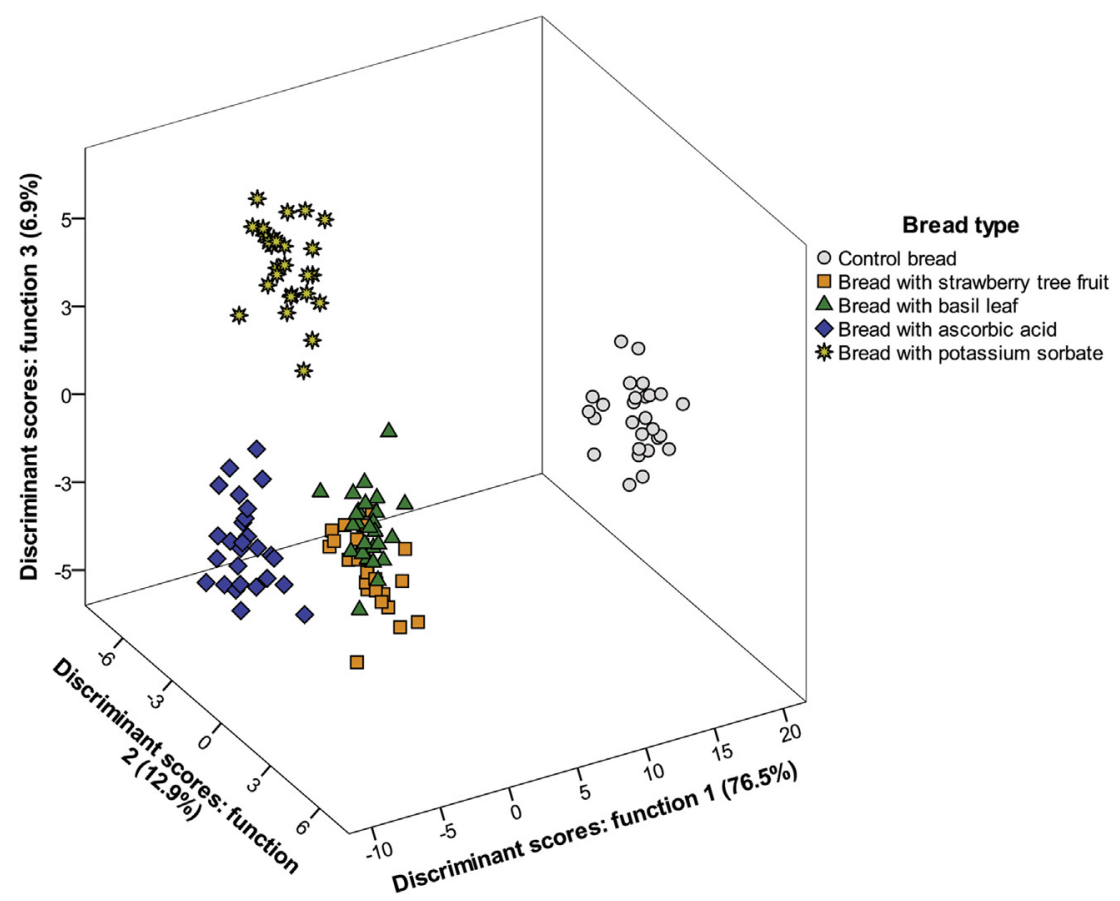

Fig. 2. Canonical discriminant functions coefficients defined from the evaluated parameters to assess the effect of bread type.

stepwise method of LDA, according to the Wilks' $\lambda$ test. Only variables with a statistically significant classification performance $(p<0.050)$ were maintained by the statistical model.

The first three defined discriminant functions included $96.3 \%$ (first function: 76.5\%; second function: 12.9\%; third function: $6.9 \%$ ) of the observed variance (Fig. 2). Among the 32 inserted variables, the model selected water, fat, ash, energy, $\mathrm{pH}, a^{*}$ (top crust), $L^{*}$ (interior), $a^{*}$ (interior), $b^{*}$ (interior), fructose, glucose, trehalose, sugars, DPPH scavenging activity and reducing power as the ones with the highest discriminant effect. Function 1, which was mostly correlated (data not shown) with DPPH scavenging activity and reducing power, separating markers corresponding to control bread and a second group formed by all the incorporated loaf breads, specifically by the lower $\mathrm{EC}_{50}$ values of the last. Function 2 was particularly useful to separate markers corresponding to bread incorporated with $A$. unedo fruit and $O$. basilicum leaves from those incorporated with the commercial compounds (ascorbic acid and potassium sorbate), mainly due to the differences in $L^{*}, a^{*}$ (lower in breads with natural extracts) and trehalose (higher in breads with natural extracts), the three variables with the highest correlation with function 2. To finish, function 3 was more highly correlated to (ordered by correlation factor) water, fructose, energy and ash, defining two distinct groups: one constituted by the markers corresponding to bread with $A$. unedo fruit extract + bread with ascorbic acid (with higher water values), and a second one formed by markers corresponding to bread with $O$. basilicum leaves extract + bread with potassium ascorbate (with higher fructose, energy and ash contents).

In the performed LDA, the classification performance was $100 \%$ accurate, either for original grouped cases, as well as for the crossvalidated grouped cases.

Overall, it was possible to verify that the studied natural extracts might represent alternatives to commercial additives such as ascorbic acid or potassium sorbate, depending on the intended preservative effect.

\section{Acknowledgements}

The authors are grateful to the Foundation for Science and Technology (FCT, Portugal) and FEDER under Programme PT2020 for financial support to CIMO (UID/AGR/00690/2013), C. Caleja (SFRH/BD/93007/2013) grant and L. Barros and J. Barreira contracts. To FCT and FEDER under Programme NORTE2020 for the project NORTE-01-0145-FEDER-023289. To the Serbian Ministry of Education, Science and Technological Development, grant number 173032.

\section{References}

Albuquerque, B. R., Prieto, M. A., Barreiro, M. F., Rodrigues, A., Curran, T. P., Barros, L. et al. (2017). Catechin-based extract optimization obtained from Arbutus unedo L. fruits using maceration/microwave/ultrasound extraction techniques. Indus trial Crops and Products, 95, 404-415. doi.org/10.1016/j.indcrop.2016.10.050.

Andrade, D., Gil, C., Breitenfeld, L., Domingues, F., \& Duarte, A. P. (2009). Bioactive extracts from Cistus ladanifer and Arbutus unedo L. Industrial Crops and Products, 30(1), 165-167.

AOAC. (2016). AOAC official methods of analysis (20th ed.) (AOAC INTERNATIONAL).

Barreira, J. C. M., Pereira, J. A., Oliveira, M. B. P. P., \& Ferreira, I. C. F. R. (2010). Sugars profiles of different chestnut (Castanea sativa Mill.) and almond (Prunus dulcis) cultivars by HPLC-RI. Plant Foods for Human Nutrition, 65(1), 38-43.

Barros, L., Carvalho, A. M., Morais, J. S., \& Ferreira, I. C. F. R. (2010). Strawberry-tree, blackthorn and rose fruits: Detailed characterization in nutrients and phytochemicals with antioxidant properties. Food Chemistry, 120, 247-254.

Barros, L., Pereira, E., Calhelha, R. C., Dueñas, M., Carvalho, A. M., Santos-Buelga, C. et al. (2013). Bioactivity and chemical characterization in hydrophilic and lipophilic compounds of Chenopodium ambrosioides L. Journal of Functional Foods, 5, 1732-1740.

Berdahl, D. R., Nahas, R. I., \& Barren, J. P. (2010). 12-Synthetic and natural antioxidant additives in food stabilization: Current applications and future research. In Oxidation in foods and beverages and antioxidant applications (pp. 272-320). http://doi.org/. https://doi.org/10.1533/9780857090447.2.272.

Bessada, S. M., Barreira, J. C. M., Barros, L., Ferreira, I. C. F. R., \& Oliveira, M. B. P. P. (2016). Phenolic profile and antioxidant activity of Coleostephus myconis (L.) Rchb. f.: An underexploited and highly disseminated species. Industrial Crops and Products, 89, 45-51.

Bolarinwa, I. F., Aruna, T. E., \& Raji, A. O. (2017). Nutritive value and acceptability of bread fortified with moringa seed powder. Journal of the Saudi Society of Agricultural Sciences. http://doi.org/10.1016/j.jssas.2017.05.002.

Branen, A. L., Davidson, P. M., Salminen, S., \& Thorngate, J. (2001). Food additives. New York: Taylor \& Francis. 
Caleja, C., Barros, L., Antonio, A. L., Carocho, M., Oliveira, M. B. P. P., \& Ferreira, I. C. F. R. (2016b). Fortification of yogurts with different antioxidan preservatives: A comparative study between natural and synthetic additives. Food Chemistry, 210, 262-268.

Caleja, C., Barros, L., Antonio, A. L., Ciric, A., Sokovic, M., Oliveira, M. B. P. P., et al. (2015). Foeniculum vulgare Mill. as natural conservation enhancer and health promoter by incorporation in cottage cheese. Journal of Functional Foods, 12, $428-438$.

Caleja, C., Ribeiro, A., Barros, L., Barreira, J. C. M., Antonio, A. L., Oliveira, M. B. P. P. et al. (2016a). Cottage cheeses functionalized with fennel and chamomile extracts: Comparative performance between free and microencapsulated forms Food Chemistry, 199, 720-726.

Carocho, M., Barreira, J. C. M. Antonio, A. L, Bento, A. Morales, P., \& Ferreira, I. C. F. R. (2015b). The incorporation of plant materials in "Serra da Estrela" cheese improves antioxidant activity without changing the fatty acid profile and visual appearance. European Journal of Lipid Science and Technology, 117(10), 1607-1614.

Carocho, M., Barreiro, M. F., Morales, P., \& Ferreira, I. C. F. R. (2014). Adding molecules to food, pros and cons: A review of synthetic and natural food additives. Comprehensive Reviews in Food Science and Food Safety, 13, 377-399.

Carocho, M., Barros, L., Barreira, J. C. M., Calhelha, R. C., Soković, M., FernándezRuiz, V., et al. (2016). Basil as functional and preserving ingredient in "Serra da Estrela" cheese. Food Chemistry, 207, 51-59.

Carocho, M., Morales, P., \& Ferreira, I. C. F. R. (2015a). Natural food additives: Quo vadis? Trends in Food Science and Technology, 45, 284-295.

Debonne, E., Van Bockstaele, F., Philips, E., De Leyn, I., \& Eeckhout, M. (2017). Impact of par-baking and storage conditions on the quality of par-baked and fully baked bread. LWT - Food Science and Technology, 78, 16-22.

Fernandes, Â., Antonio, A. L., Barreira, J. C. M., Oliveira, M. B. P. P., Martins, A., \& Ferreira, I. C. F. R. (2012). Effects of gamma irradiation on physical parameters of Lactarius deliciosus wild edible mushrooms. Postharvest Biology and Technology, $74,79-84$

Fortalezas, S., Tavares, L., Pimpão, R., Tyagi, M., Pontes, V., Alves, P. M., et al. (2010). Antioxidant properties and neuroprotective capacity of strawberry tree fruit (Arbutus unedo). Nutrients, 2(2), 214-229.

Gomes, M. F. F. N. (2011). Strategies for the Improvement of Arbutus unedo L (Strawberry Tree): In vitro Propagation, Mycorrhization and Diversity Analysis. Ph.D. Thesis. Coimbra, Portugal: Universidade de Coimbra.

Guimarães, R., Barros, L., Dueñas, M., Carvalho, A. M., Queiroz, M. J. R. P., SantosBuelga, C., et al. (2013). Characterisation of phenolic compounds in wild fruits from Northeastern Portugal. Food Chemistry, 141, 3721-3730.

Motarjemi, Y., Moy, G., \& Todd, E. (2014). Encyclopedia of food safety (1st ed.).
Missouri, USA: Elsevier.

Oliveira, I., Baptista, P., Malheiro, R., Casal, S., Bento, A., \& Pereira, J. A. (2011). Influence of strawberry tree (Arbutus unedo L.) fruit ripening stage on chemical composition and antioxidant activity. Food Research International, 44, $1401-1407$.

Pereira, E. Barros, L, Barreira, J. C. M. Carvalho, A. M. Antonio, A. L, \& Ferreira, I. C. F. R. (2016). Electron beam and gamma irradiation as feasible conservation technologies for wild Arenaria Montana L.: Effects on chemical and antioxidant parameters. Innovative Food Science \& Emerging Technologies, 36, 269-276.

Sciarini, L. S., Ribotta, P. D., León, A. E., \& Pérez, G. T. (2012). Incorporation of several additives into gluten free breads: Effect on dough properties and bread quality. Journal of Food Engineering, 111(4), 590-597.

Singh, N., Jha, A., Chaudhary, A., \& Upadhyay, A. (2012). Enhancement of the functionality of bread by incorporation of Shatavari (Asparagus racemosus). Journal of Food Science and Technology, 51(9), 2038-2045.

Soković, M., Glamoćlija, J., Marin, M. D., Brkić, D., \& van Griensven, L. J. L. D. (2010). Antibacterial effects of the essential oils of commonly consumed medicinal herbs using an in vitro model. Molecules, 15, 7532-7546.

Soković, M. \& van Griensven, L. J. L. D. (2006). Antimicrobial activity of essential oils and their components against the three major pathogens of the cultivated button mushroom, Agaricus bisporus. European Journal of Plant Pathology, 116, $211-224$.

Stopforth, J. D., Sofos, J. N., \& Busta, F. F. (2005). Sorbic acid and sorbates. In P. M. Davidson, J. N. Sofos, \& A. L. Branen (Eds.), Antimicrobials in food (pp. 49-90). Boca Raton: CRC Press.

Tomaska, L. D., \& Tharwa, A. C. T. (2014). Australia S brooke-Taylor, bright, food additives-general VIC, Australia. https://doi.org/10.1016/B978-0-12-3786128.00234-1.

Viator, C., Blitstein, J., Brophy, J. E., \& Fraser, A. (2015). Preventing and controlling foodborne disease in commercial and institutional food service settings: A systematic review of published. Intervention Studies Journal of Food Protection, 78, 446-156.

Vlase, L, Benedee, D., Hanganu, D., Damian, G., Csillag. I., Sevastre, B., et al, (2014). Evaluation of antioxidant and antimicrobial activities and phenolic profile for Hyssopus officinalis, Ocimum basilicum and Teucrium chamaedrys. Molecules, 19, 5490-5507.

Zielinski, A. A. F., Haminiuk, C. W. I., Alberti, A., Nogueira, A., Demiate, I. M., \& Granato, D. (2014). A comparative study of the phenolic compounds and the in vitro antioxidant activity of different Brazilian teas using multivariate statistical techniques. Food Research International, 60, 246-254. 